\title{
A INFLUÊNCIA DA GLOBALIZAÇÃO NA QUALIFICAÇÃO DOS PROFISSIONAIS DO SETOR DE TURISMO
}

\section{THE INFLUENCE OF GLOBALIZATION ON THE QUALIFICATION OF PROFESSIONALS FROM THE TOURISM SECTOR}

\author{
Marília Barbosa Gonçalves ${ }^{1}$ \\ Messalina Karoline Oliveira Lod ${ }^{2}$ \\ Artur Manuel Marulo ${ }^{3}$
}

\begin{abstract}
RESUMO
A globalização tem provocado mudanças no perfil e no comportamento do consumidor e nas relações comerciais, exigindo que o mercado adapte-se e avance juntamente à velocidade desse fenômeno. Para acompanhá-lo, indústria e setores de prestação de serviço têm inovado e se aprimorado cada vez mais, não só no que oferecem, mas também em como oferecem, para satisfazer aos seus clientes. A fim de atender as exigências desse consumidor, o mercado busca, então, profissionais mais qualificados. No turismo, não foi diferente, o setor sofreu consequências positivas e negativas, devido à globalização. Visando a prestação de um serviço de excelência, os profissionais devem se qualificar tanto em conhecimentos gerais, como também específicos do setor. Usando uma metodologia literária, baseada em autores, como Bauman (1999), Giddens (2007), Bourdieu (1977), este artigo discute, mediante olhar crítico, a influência da globalização na qualificação dos profissionais de turismo.
\end{abstract}

Palavras-chave: Globalização. Consumidor. Profissional de Turismo.

\begin{abstract}
Globalization has caused changes in the profile and behavior of consumers and in trade relations, requiring the market to adapt and move along at the speed of this phenomenon. To follow these changes, the industry and service sectors have innovated and improved, not only in what they offer, but also on how to offer in order to satisfy their customers. In order to meet consumer demands, the market looks for the most qualified professionals. It was not different in tourism, the sector suffered positive and negative consequences due to globalization. Aiming to provide an excellent service, professionals must qualify both in terms of general knowledge, as well as specific knowledge. Using a literature based research methodology based on authors such as Bauman (1999), Giddens (2007), Bourdieu (1977), this article discusses the influence of globalization on the qualification of tourism professionals.
\end{abstract}

Keywords: Globalization. Consumer. Tourism Professional.

\footnotetext{
${ }^{1}$ Mestranda em Turismo pela Universidade Federal do Rio Grande do Norte - UFRN. Especialista em Marketing Estratégico pelo Centro Universitário do Rio Grande do Norte - UNI-RN. Bacharel em Turismo pela Universidade Federal do Rio Grande do Norte - UFRN. E-mail: mariliagoncalves_rn@hotmail.com.

${ }^{2}$ Mestranda em Turismo pela Universidade Federal do Rio Grande do Norte - UFRN. Bacharel em Turismo pela Universidade Federal do Rio Grande do Norte - UFRN. E-mail: mess_karoline@hotmail.com.

${ }^{3}$ Mestre em Turismo pela Universidade Federal do Rio Grande do Norte - UFRN. Especialista em Gestão Ambiental pela Universidade Potiguar - UNP. Tecnólogo em Turismo e Gestão de Empresas Turísticas pela Universidade Politécnica de Maputo/ Moçambique. E-mail: arturmarulo@hotmail.com.
} 


\section{Introdução}

O fenômeno da globalização ocasionou mudanças nos hábitos de vida do ser humano. Como afirma Bedin (1997, p. 134), a configuração do mundo como um sistema global é o mais significativo acontecimento político, econômico e social das duas últimas décadas. Além disso, constitui em si mesmo, um marco simbólico-referencial indicativo da emergência de um novo século na história da humanidade e, coincidentemente, de uma nova etapa de seu desenvolvimento. O fenômeno da globalização possui um alcance abrangente, exigindo a elaboração de "um novo paradigma, para a compreensão dos diferentes aspectos da realidade contemporânea" (SANTOS, 1997.p.48).

Giddens (2007, p.17) discute o conceito de globalização em Mundo em Descontrole, no qual afirma que vivemos num mundo de transformações, que afetam quase todos os aspectos do que fazemos. Para o bem ou para mal, estamos sendo impelidos rumo a uma ordem global que ninguém compreende plenamente, mas cujos efeitos se fazem sentir sobre nós. Logo, pode-se dizer que globalização é um fenômeno que alterou profundamente diversas relações na sociedade, como a família, a tradição e a própria democracia. As relações de trabalho também têm sofrido influências decorrentes desse processo, uma vez que os profissionais de todos os setores econômicos precisam se atualizar e manter um ritmo polivalente para o bom desempenho de suas funções, o que é imprescindível em alguns setores, como, por exemplo, no turismo.

Uma pequena reflexão acerca do trabalho prestado por esse profissional, mostra o quão ele tem por base a necessidade de conhecimento e desenvoltura na área de comunicação, no conhecimento de outros idiomas, na necessidade da poli-valência, na flexibilidade para vários segmentos, na postura profissional adequada, dentre outras competências.

Os efeitos gerados pela globalização estão intrinsecamente ligados às mudanças ocasionadas no setor de turismo, bem como no dia a dia do profissional que atua neste setor. Assim, o presente artigo busca fazer uma reflexão sobre como os profissionais do setor turístico estão se adaptando a essas mudanças e aprimorando seus conhecimentos para não serem retirados e/ou substituídos no mercado, devido ao fenômeno da globalização. Para conduzir essa reflexão, este estudo teórico se baseia, sobretudo, no pensamento de Giddens (2007 ) e Bauman (1999), entre diversos outros autores, tendo como principal pressuposto a influência que a globalização possui sobre o comportamento do consumidor, e como os profissionais do turismo estão se adaptando, aperfeiçoando seus conhecimentos para atendê-los, diante de um mercado globalizado.

A educação para o turismo tem sido direcionada à capacitação profissional, ou seja, ao ensino dos futuros profissionais ${ }^{4} \mathrm{em}$ virtude de conhecimentos de etiqueta e comportamento adequado em relação ao turista. É clara a existência de uma estruturação mecanizada característica dos trabalhadores do turismo, envolvendo comportamentos nem sempre espontâneos, como a necessidade de sorrir e manter-se continuamente prestativo e atencioso em relação às necessidades do turista.

O setor turístico fundamenta-se na venda e prestação de serviços de qualidade, seus responsáveis são profissionais que terão que lidar com outras pessoas. Embora a "simpatia" desses trabalhadores não ocorra de forma totalmente natural, devido às próprias características de suas funções, a capacitação dos profissionais dessa área tem seguido uma linha em comum. Silva (2007) complementa esse pensamento da seguinte maneira:

Os métodos de ensino, em grande parte das escolas, são comportamentalistas, behavioristas. Ensinam como fazer, sem discutir ou contextualizar o tema. O resultado deste processo é, em curto tempo, um comportamento universal e padronizado. Basta observarmos como somos tratados nos hotéis. Não há uma vinculação pessoal nas relações sociais estabelecidas. Percebe-se que o tratamento dispensado aos turistas é igual, e muitas vezes artificial. Quantos sorrisos artificiais presenciamos nas relações estabelecidas entre o turista e o profissional do turismo?

O profissional em turismo da era globalizada deve manter-se atualizado em meio à sociedade informacional que vivenciamos, considerando-se que praticamente toda a troca de informações atual envolve o uso de computadores e consulta ao mundo virtual. Um profissional da área deve dotar-se de

\footnotetext{
${ }^{4} \mathrm{O}$ profissional de turismo ao qual estamos nos referindo é aquele que atua
} como técnico ou tecnólogo da área e não o Bacharel em Turismo. 
uma diversidade de conhecimentos adicionando às suas ferramentas o domínio das novas tecnologias, idiomas e conhecimento cultural, no intuito de alcançar sucesso dentro de seu trabalho. Esse profissional deve ser curioso e buscar conhecer a cultura e os hábitos dos turistas que estão visitando o destino, tanto aqueles provenientes de outros países, quanto de outras regiões do país. Esses aspectos serão diferenciais para o seu crescimento profissional, tendo em vista que grande parte dos turistas é formada por estrangeiros: europeus, norte-americanos, sul-americanos, entre outras procedências.

Este trabalho não visa estabelecer uma visão definitiva ou acabada sobre o tema, mas apresentar um ensaio crítico em relação ao que foi discutido na literatura e em relação à atual formação dos profissionais em turismo, servindo de base para novas pesquisas que abranjam toda a complexidade que envolve o processo de globalização e trabalho no setor turístico.

\subsection{Algumas Considerações sobre o Fenômeno da Globalização}

Para entender o impacto da globalização no turismo, precisamos tomar conhecimento das discussões levantadas em relação ao tema. Santos (2002), por exemplo, considera esse fenômeno como um simples processo transfronteiriço e transnacional de sistemas de produção, de transferência financeira, de disseminação do uso da tecnologia e da informação, e até o deslocamento de pessoas em escala mundial. A globalização, segundo o autor, teria, então, um caráter voltado à evolução econômica de forma geral, tratando-se portanto, de uma consequência do desenvolvimento.

Giddens (2007, p. 21) lembra que o fenômeno correspondente a uma intensa troca de informações por todo o mundo, em um tempo-espaço mínimo, teria começado a surgir a partir do desenvolvimento de sistemas de comunicação no final da década de 1960, os satélites. O novo sistema de transmissão foi rapidamente substituindo as velhas tecnologias, logo o código Morse ${ }^{5}$ passou a ser menos utilizado, desa-

\footnotetext{
5 "Em meados do século XIX, um pintor de retratos de Massachusetts, Samuel Morse, transmitiu a primeira mensagem, "Qual foi a obra de Deus?", por telégrafo elétrico.
}

parecendo de cena em 1999, surgindo pela primeira vez a comunicação instantânea de um lado ao outro do mundo com o crescimento no número desses transmissores

Mas não parou por aí, com o avanço da tecnologia, as novas formas de comunicação foram atualizando-se e tornando-se mais acessíveis à população, ocasionando uma transformação global na vida e cotidiano das pessoas. Tal transformação é refletida na necessidade de aquisição de conhecimentos de forma quase instantânea, na necessidade de comunicação e compreensão das diferenças culturais e idiomáticas, nas relações pessoais e profissionais como um todo, e em uma aceitação de normas e padrões internacionais no trabalho, ambas influenciadas pela globalização. A velocidade de difusão das informações foi ainda mais impulsionada com o advento da Internet, que em poucos anos alcançou milhares de usuários, modificando as relações sociais e profissionais em todo o mundo.

A globalização oferece, sem dúvida, oportunidades para o desenvolvimento humano desde o avanço tecnológico, a interligação e a interdependência dos mercados financeiros. Em escala mundial, encurtaram as distâncias, unificaram e melhoraram o acesso à informação, promovendo a padronização da cultura e do comportamento por meio de novas tecnologias de informação e comunicação que se tornaram cada vez mais acessíveis em escala global.

A globalização esta na ordem do dia, uma palavra da moda que se transforma rapidamente em um lema, uma encantação mágica, uma senha capaz de abrir as portas de todos os mistérios presentes e futuros, é o destino irremediável do mundo, um processo irreversível, é também um processo que nos afeta a todos na mesma medida e da mesma maneira. Estamos todos sendo globalizados e isso significa basicamente o mesmo para todos. (BAUMAN, 1999. p. 7).

Bauman (1999) lembra que a imagem da globalização coloca-a radicalmente à parte de outra ideia que aparentemente substituiu a da "universalização". Esta transmitia a esperança, a intenção e a determinação de se produzir a ordem; além do que

Ao fazê-lo deu início a uma nova fase na história do mundo. Nunca antes uma mensagem pudera ser enviada sem que alguém a transportasse até algum lugar." (GIDDENS,2007) 
os outros termos afins assinalavam, ela indicava uma ordem universal - a produção da ordem numa escala universal, verdadeiramente global. No entanto, nada disso restou no significado de globalização, tal como formulado no discurso atual. $\mathrm{O}$ novo termo refere-se primordialmente aos efeitos globais, notoriamente não pretendidos e imprevistos, e não às iniciativas e aos empreendimentos globais.

O autor $(1999$, p. 9) ainda ressalta que a globalização tanto divide como une, divide enquanto une, e as causas da divisão são idênticas as que promovem a uniformidade do globo conjuntamente, os dois processos intimamente relacionados diferenciam nitidamente as condições existências de populações inteiras e de vários segmentos de cada população.

Conforme Kavanagh (apud BAUMAN, 1999) a globalização deu mais oportunidades aos extremamente ricos de ganhar dinheiro mais rápido, beneficiando da mais avançada tecnologia para movimentar o seu capital. Consequentemente, a globalização é um paradoxo, sendo benéfico para muitos, mas deixando de fora ou marginalizando a maioria da população mundial.

Nessa linha de pensamento, Seabrook (apud BAUMAN, 1999) considera que, na sociedade globalizada, a questão da pobreza não deve ser vista como fator alheio à globalização dominada pelo capitalismo, pelo contrário, é uma evidencia de saúde e robustez do seu ímpeto para acumulação e esforços sempre maiores, razão pela qual a pobreza não pode ser considerada sintoma da doença do capitalismo.

A globalização enfraquece o Estado, fazendo-o dobrar-se perante as decisões tomadas internacionalmente, fazendo lembrar o tempo da colonização, ou seja, do domínio, como considera BAUMAN (1999). A globalização nada mais é que a extensão totalitária de sua lógica a todos os aspetos da vida. Os estados não têm recursos suficientes nem liberdade de manobra para suportar a pressão, pela simples razão de o estado e as empresas caírem num colapso, no final é somente deixado com suas necessidades básicas, sua base material destruída, sua soberania e independência anuladas, sua classe política apagada, tornando-se um mero servidor dos anseios do capital.

O significado mais profundo da globalização é o do caráter indeterminado, indisciplinado e de autopropulsão dos assuntos mundiais; a ausência de um centro de um painel de controle, de uma comis- são diretora, de um gabinete administrativo sendo portando considerada a nova desordem mundial. (BAUMAN, 1999, p. 67).

Entende-se que a globalização somente cria maiores benefícios às nações mais industrializadas do mundo, que veem nos países subdesenvolvidos oportunidade de exportar o seu capital, visto que seu mercado local encontra-se saturado por grandes multinacionais que entram nos países subdesenvolvidos, tornando os governos locais refém das suas políticas e, acima de tudo, promovendo em escala inferior os benefícios dos investimentos realizados.

O surgimento da Internet foi o grande propulsor do fenômeno da globalização, ao encurtar as barreiras e "diminuir distâncias" entre os continentes. Estimulou o consumismo por produtos importados que passaram a ser mais vendidos com o auxílio das compras eletrônicas pela Internet, e provocou mudanças no comportamento do consumidor nas diversas áreas, entre elas destaca-se aqui o turismo. A Internet permitiu que o turista fosse mais independente, e isso causou sérios impactos dentro do setor, tanto positivos, como a facilidade ao acesso das informações e barateamento do preço de serviços turísticos, quanto negativos, gerando crise no setor das agências de viagens, com o processo de desintermediação dos agentes, entre outras ações.

\subsection{O Turista na Sociedade do Consumo e da Informação}

Nas últimas décadas do século XX, assistiu-se a transformação da sociedade em uma sociedade de consumo, decorrente do desenvolvimento industrial, impulsionada em grande medida pelo fenômeno da globalização, que em certo momento fez com que se tornasse mais difícil vender os produtos e serviços do que fabricá-los. Esse excesso de oferta exigiu a criação de melhores e mais sedutoras estratégias de marketing, objetivando atrair demanda e criar um sistema de consumo capaz de absorver os bens e serviços produzidos.

O consumo sempre fez parte de toda a história da existência humana. No entanto, Bauman (1999) estabelece a diferença entre a sociedade moderna característica da globalização e a sociedade que anteriormente nos antecedeu, considerando que a nossa 
sociedade é uma sociedade de consumo no sentido similarmente profundo e fundamental, diferente da sociedade dos nossos predecessores, que correspondia a uma sociedade de produtores. A grande diferença reside no fato de a sociedade de consumo conceber os seus membros de modo que estes assumam, acima de tudo, o papel de consumidor.

Como todas as outras sociedades, a sociedade de consumo é uma sociedade estratificada, podendo-se distinguir indivíduos de grupos diferentes, nomeadamente os indivíduos pertencentes à classe alta e o grupo de indivíduos pertencentes à classe baixa, cuja principal diferença reside no seu grau de mobilidade em relação ao seu poder de escolha e de opção de aquisição de bens e serviços. Em relação a esse aspecto, Bauman (1999, p.94) considera que "todos podem ser lançados na moda do consumo, todo mundo pode desejar ser consumidor e aproveitar as oportunidades que esse modo de vida oferece, mas nem todo mundo pode ser consumidor".

Bauman (1999) afirmara que para assegurar um lugar no mercado desregulamentado da competitividade global e conquistar cada vez mais o seu público-alvo, os bens e serviços devem despertar desejo, e, para isso, devem seduzir os possíveis consumidores e afastar os competidores, devendo posteriormente abrir espaço para outros produtos capazes de provocar desejo, do contrário a caça global dos lucros vai parar. No entanto, para aumentar sua capacidade de consumo, os consumidores não devem nunca ter descanso. Precisam ser mantidos acordados e em alerta sempre, continuamente expostos a novas tentações, num estado de excitação incessante, e, também, com efeito, em estado de perpétua insatisfação.

As novas tecnologias da informação e comunicação têm influenciado muito esse "novo consumidor", transformando-o no que Kotler (2010) chama de "prosumidor" (produtor + consumidor). Ele quer expor e propagar suas ideias, de forma que elas colaborem tanto para as empresas como para outros consumidores, e a tecnologia permite isso. A nova onda de tecnologia permite a conectividade e a interatividade entre indivíduos e grupos. Sendo ela formada por três grandes forças: computadores e celulares baratos, Internet de baixo custo e fonte aberta; e marca a era da participação, na qual as pessoas criam e consomem notícias, ideias e entretenimento.
Poon (1993 apud QUEVEDO, 2010, p. 25) já afirmara que todas essas mudanças que vêm ocorrendo no mundo, e que possibilitaram um novo olhar sobre o fenômeno turístico, também contribuíram para a formação de um novo turista.

Stwarbrooke e Horner (2002 apud QUEVEDO, 2010 , p. 25-26) diziam e previam que o comportamento do turista futuro seria influenciado por uma série de fatores que inevitavelmente ocasionariam quatro desdobramentos, quais sejam:

a) $\mathrm{O}$ crescimento do turismo de saídas de países que, até então, não eram grandes geradores de viagens turísticas internacionais;

b) A expansão da demanda de turismo por determinados grupos da sociedade;

c) $\mathrm{O}$ desenvolvimento de novos tipos de produtos turísticos;

d) As mudanças no modo de adquirir esses produtos.

A previsão feita por esses autores foi correta e aconteceu rapidamente. Nos dias de hoje, devido ao progresso dos meios de comunicação e informação, e o acesso cada vez maior às tecnologias, como resultado do processo de globalização que o mundo assiste, muitos lugares que outrora eram de difícil acesso ou quase inacessíveis tornaram-se agora acessíveis para a sociedade globalizada.

A comunicação, decorrente do fenômeno da globalização, altera a própria estrutura de vida, pois, como dirá Giddens $(2007$, p. 22) "quando a imagem de Nelson Mandela pode ser mais familiar para nós que o rosto do nosso vizinho de porta, alguma coisa mudou na natureza da experiência cotidiana".

Baumam (1999), por exemplo, até devaneia, considerando ser desnecessária a deslocação física para realização de uma viagem, graças às novas tecnologias que nos permitem conhecer qualquer lugar do mundo, e as distâncias são anuladas, tendo o espaço deixado de ser considerado obstáculo, portanto, mesmo se desejasse ficar parado seria impossível, pois o mundo encontra-se em movimento.

Stwarbrooke e Horner (2002, p. 332 apud QUEVEDO, 2007, p. 26) ressaltam que "talvez um dia o turismo se torne uma atividade inteiramente mental, sem que se precise viajar - uma atividade que se possa realizar na própria casa do turista e cujo único limite seja a sua imaginação". Porém, Naisbitt (1994, p. 166 apud QUEVEDO, 2007, p. 26) já colocava que: 
À medida que a economia mundial se integra e que a sociedade global se torna cada vez mais homogênea, as necessidades dos indivíduos de preservar um sentido de identidade em um mar de homogeneização se fortalece. Por conseguinte, as pessoas se tornam mais - e não menos - propensas a viajar, enquanto procuram preservar um sentido de continuidade e de filiação a um grupo.

No entanto, na sociedade globalizada, nem todos os indivíduos se movem pelo seu belo prazer, alguns se movem mesmo sem querer, como afirma Bauman (1999), muitos estão se movendo porque foram empurrados, tendo sido desenraizados do lugar sem perspectiva por uma força sedutora ou propulsora demais, e muitas vezes misteriosa demais para resistir. O autor comenta que os indivíduos das classes desfavorecidas são obrigados a deslocarem-se com argumento de que melhores condições de vida estão sendo criadas, mas, na realidade, são arrastados para que sejam satisfeitas as necessidades dos indivíduos da classe alta.

Portanto, no que concerne à mobilidade na sociedade pós-moderna, pode-se distinguir dois tipos diretamente relacionados com a estratificação da sociedade globalizada. Bauman (1999) explica essas diferenças usando os termos Turistas e Vagabundos para agrupar os indivíduos dentro de uma sociedade globalizada. Portanto, os turistas seriam aqueles indivíduos pertencentes à classe alta, também denominados como globalmente móveis, enquanto os vagabundos são indivíduos da classe baixa e também designados como localmente amarrados.

$\mathrm{Na}$ era da globalização tanto o turista como o vagabundo fazem parte da sociedade de consumo, porém existe grande diferença entre esses dois grupos sociais, como destaca Bauman (1999), tanto o turista como o vagabundo foram transformados em consumidores, mas o vagabundo é um consumidor frustrado. Os vagabundos não podem realmente se permitir às opções sofisticadas em que se espera que sobressaiam os consumidores, seu potencial de consumo é tão limitado quanto seus recursos. Embora se saiba que, no contexto atual, as principais operadoras de viagens e grandes hotéis se mantêm por meio do turismo de massa, sustentados pela classe média, de recurso mais limitado, que encontrou nos pacotes turísticos, parcelados em "n" vezes nos cartões de crédito, uma maneira de viajar, distrair-se e poder conhecer lugares antes destinados apenas à classe alta.

\subsection{A Qualificação dos Profissionais do Setor de Turismo}

Os serviços oferecidos aos turistas pelos profissionais de Turismo e Hotelaria refletem, de forma geral, a qualidade da Educação que lhes foi oferecida durante seus processos de profissionalização. Essa educação, aliada ao talento natural de quem aprecia trabalhar com o público e com o Turismo, é responsável por tornar parte do período de viagem de um turista muito mais interessante. A qualidade da educação oferecida a esses profissionais reflete-se no desenvolvimento dos seus trabalhos em seus cotidianos. A busca pela perfeição na prestação dos serviços é uma das principais metas do mercado turístico e hoteleiro. Espera-se que um turista perceba a qualidade com a qual os serviços são prestados, deduzindo, dessa forma, a qualidade do treinamento que o profissional que o está atendendo recebeu.

A Educação profissional em turismo é um tema que vem sendo difundido e discutido em diversos países, inclusive no Brasil, buscando-se melhores abordagens que possam resultar em bons desempenhos dos funcionários das empresas turísticas. Rakadjiyska (1990) descreveu a situação na Bulgária e os problemas relacionados ao sistema de educação e treinamento, citando que em

pesquisas regulares sobre a opinião dos turistas desde 1967 [...] as reclamações mais comuns referem-se às atitudes dos funcionários em relação aos turistas e à qualidade dos seus serviços; falhas na produção e organização de produtos turísticos; e à performance dos funcionários no trabalho. (RAKADJIYSKA, 1990, p. 151)

A autora ainda destacou que gestores de empreendimentos turísticos reportaram que $68 \%$ do seu pessoal que frequentou algum treinamento melhorou sua performance no trabalho; $28 \%$ raramente aplicam qualquer coisa que aprenderam no trabalho e $4 \%$ não mudam a sua performance no trabalho. Os melhores resultados foram reportados pelo pessoal treinado como recepcionistas, gerentes, ou Guias de Turismo. Destes, $71 \%$ disseram ter melhorado suas performances. 
Para Spinelli (2002), o crescimento acelerado do turismo requer que o sistema educativo desempenhe um papel mais ativo na formação e na qualificação dos recursos humanos que servem de apoio ao setor, já que são necessários profissionais capazes de participar de maneira eficiente no desenvolvimento do turismo em cada país. Os benefícios da educação e do treinamento em turismo definem um

círculo vicioso, num processo que se inicia no profissional bem treinado em turismo, que produzirá um resultado melhor e melhor nível de serviço para a crescente demanda turística. Funcionários bem treinados e bem pagos oferecem melhor serviço para os clientes e maior produtividade para a companhia e tornam a empresa e o país mais ricos, beneficiando visitantes e residentes. Os visitantes retornam, reforçando o círculo. (COOPER, SHEPHERD; WESTLAKE, 2001, p. 182).

A educação profissional em Turismo percorre muitos desafios para que as instituições de ensino estabeleçam um padrão de qualidade dos seus cursos e criem formas para atingir esse padrão. O Turismo, por si só, é um assunto que implica estudo de uma diversidade de disciplinas interligadas, o que o torna bastante complexo para quem o estuda e para que o padrão de qualidade do ensino em Turismo seja estabelecido. Essa mesma diversidade de disciplinas é responsável por fornecer aos estudantes da área do Turismo melhor direcionamento e compreensão do que é o Turismo.

Como lembram os autores Cooper, Shepherd e Westlake (1994, p. 48), referindo-se ao modelo de Jafar e Ritchie (1981) em que, por exemplo, 16 diferentes disciplinas de estudo são identificadas no Ensino Superior em Turismo, dentre elas podem ser citadas: Marketing de Turismo, Desenvolvimento e Planejamento do Turismo, Gerenciamento de recreação, Turismo Rural, Projeto de Paisagem, Geografia do Turismo, Relacionamento anfitrião-hóspede, Motivação para o turismo, Economia do Turismo, Sociologia do Turismo, Educação para o turismo, Estudos da Hospitalidade, Fundamentos do Transporte, Gerenciamento de Organizações turísticas, Legislação turística.

Para que o profissional de turismo/hotelaria seja competente no exercício da sua profissão, é necessário que sua formação contemple tanto aspectos teóricos como práticos. Com o objetivo de conhecer como essa equação se concretizava, interrogou-se em um estudo realizado no Brasil a respeito do percentual dos docentes que tinham experiência prática na área, (...) 69\% dos que responderam a essa questão afirmam que somente $50 \%$ dos docentes do seu curso têm experiência prática em turismo/hotelaria. (SALGADO; CURADO, 2002, p. 189).

No ensino em turismo, as três principais abordagens incluem a abordagem puramente vocacional em que o estudante é direcionado a um cargo dentro do trade turístico; cursos desenvolvidos com a visão de que o turismo é uma atividade merecedora de estudo, cuja quantidade cresce rapidamente e, finalmente, os cursos que usam o turismo como uma ilustração para enriquecer disciplinas tradicionais e áreas relacionadas. O turismo nesse último contexto é visto como um meio e os alunos não esperariam ser empregados na área turística.

O desenvolvimento do turismo como objeto de estudo, nas últimas décadas, tem sido visto como real transição em foco ou importância, pois esse tema vem sendo reconhecido como área de conhecimento que possui brilho próprio e, mesmo com pouca credibilidade, a infraestrutura intelectual do turismo está crescendo rapidamente (COOPER, SHEPHERD; WESTLAKE, 1994).

Esses mesmos autores relembram que o turismo, embora seja complexo e atraente como área de estudo, enfrenta diversos desafios, como o desacordo entre o governo e a academia quanto ao que constitui o setor turístico, afeta as necessidades de educação e treinamento já que esse setor não está fundamentalmente definido e nem suas atividades estão completamente documentadas. Além de ser dominado por pequenas empresas lideradas por empresários que não possuem treinamento formal em turismo e não reconhecem a necessidade de participarem de cursos relacionados à área e aumentar o profissionalismo global da indústria, além de poder ser identificado como uma área de estudo "soft". Ignorância e falta de credibilidade em relação ao assunto parece generalizada e enraizada. Ansarah (2002) afirma que para o desenvolvimento do turismo, no sentido de se caracterizar como uma oferta de qualidade, faz-se necessária uma formação profissional também de qualidade. 
Para Spinelli (2002), o turismo como motivo de estudo apresenta possibilidades de exploração ilimitadas. Isso fica claro quando se observa a infinidade de aspectos do cotidiano que costumam abranger setores econômicos que estão direta ou indiretamente envolvidos com o turismo. Esses aspectos envolvem diversas áreas do conhecimento: psicologia, meio ambiente, aprendizado de idiomas, artes, culinária, etc. Para chegar-se a essa conclusão, basta imaginar a rotina de um turista: a contratação de meios de transporte, o incentivo à preservação do patrimônio histórico e cultural das regiões por meio de sua visitação, a compra do artesanato regional, a comunicação em outros idiomas dos prestadores de serviços aos turistas, a degustação da comida típica regional durante a visita ao local, entre diversos outros aspectos. Daí o primeiro problema que se apresenta na criação de planos de estudo é dividi-lo, embora seja esse somente um procedimento convencional com vistas à análise, já que, na realidade, a questão do turismo constitui uma totalidade homogênea.

Torna-se necessário que a qualidade do ensino nas escolas de turismo e hotelaria seja elevada, promover-se a integração entre as entidades docentes e as empresas do setor turístico e estimular-se as instituições de ensino a aprimorar o nível acadêmico de seus currículos.

Para Spinelli (2002), a qualidade dos serviços turísticos é um tema relevante para o futuro do setor, à medida que o turista torna-se cada vez mais inteligente em relação aos recursos que lhes são oferecidos, devido às possibilidades de comparação com outros destinos já visitados e à facilidade de acesso à informação. Em um mundo onde o acesso à internet é facilitado, a competitividade é característica forte da era globalizada. O turismo de qualidade, portanto, é alcançado quando existe relação estreita entre aqueles que oferecem os produtos turísticos e aqueles que os consomem.

De acordo com Mota (2011), a globalização da economia exige das empresas um alto padrão de qualidade em serviços, para sustentar o volume de demanda e consolidar o fluxo turístico nos destinos nacionais. Para tanto, faz-se necessária a contratação de pessoas qualificadas nas diversas atividades específicas de serviços requeridas pelo Turismo e Hotelaria. Assim, a grande demanda de profissionais qualificados gerou, no mercado turístico, uma demanda por qualificação que, por sua vez, incentivou o rápido crescimento da oferta de cursos relacionados a esse setor econômico.

\section{Os Impactos da Globalização sobre o Profissional de Turismo}

A educação do profissional do turismo, de forma generalizada, está se adaptando às tendências impulsionadas pela globalização, assim como todos os diversos setores educacionais. A formação dos futuros profissionais do setor de turismo, entre outros setores, provoca a necessidade do surgimento de novas metodologias de educação que proporcionem maior competitividade no mercado. O surgimento dessas novas metodologias tem provocado reformas educacionais e reestruturações para que a nova demanda seja atendida.

Ainda sobre a readequação da educação profissional, Frank Go (apud THEOBALD, 2001) cita que o desafio é encontrar um modelo educacional que possa proporcionar melhor compreensão da natureza interdependente de nosso mundo e ajudar a reformular a capacidade organizacional para, simultaneamente, competir e cooperar no ambiente global. O autor apresentou uma pesquisa que definiu dezoito competências e habilidades necessárias a um profissional do turismo e as respectivas porcentagens quanto à importância de cada característica, de acordo com a tabela 1 . 
Tabela 1 - Competências e habilidades necessárias a um profissional do turismo e suas respectivas importâncias

\begin{tabular}{l|cc|c}
\hline $\begin{array}{l}\text { HABILIDADES - CARACTERíSTICAS } \\
\text { PESSOAIS }\end{array}$ & $\mathbf{\%}$ & $\begin{array}{c}\text { HABILIDADES - CARACTERÍSTICAS } \\
\text { PESSOAIS }\end{array}$ & $\mathbf{\%}$ \\
\hline Comunicações eficientes & 97,4 & Vontade de mudar & 87,1 \\
$\begin{array}{l}\text { Perspectiva internacional (incluindo sensibilidade } \\
\text { para as diferenças nacionais) }\end{array}$ & 94,7 & Iniciativa & 85,1 \\
Habilidades criativas para a solução de problemas & 94,5 & Ética & 84,9 \\
Capacidade analítica & 93,9 & Aspectos socioculturais do turismo & 83,7 \\
Saber tomar decisões & 93,3 & Comprometimento com a aprendizagem atual & 77,1 \\
Saber planejar - organizar & 88,8 & Habilidade com o computador & 74,3 \\
Trabalhar em equipe & 88,7 & Habilidade de conhecimento experimental & 73,7 \\
Qualidades de liderança & 87,5 & Espírito Empresarial (assumir riscos) & 71,2 \\
Conhecimento de idioma estrangeiro & 69,4 & Geografia do mundo e do turismo & 63,0 \\
\hline
\end{tabular}

Fonte: Frank Go apud Theobald (2001)

Ao observar essa tabela, percebe-se que tais características estão relacionadas às atuais necessidades do mercado globalizado. Neste estudo teórico, algumas dessas características serão discutidas de forma mais ampla, tais como a diversidade cultural e idiomática, a informática e a postura do profissional do turismo em relação aos turistas.

O profissional do turismo, devido à própria natureza do Turismo como fenômeno globalizado, deverá se adaptar à possibilidade de convivência com uma infinita diversidade cultural, de hábitos e costumes de pessoas vindas de vários lugares do mundo. Da mesma forma, o turista deverá se adaptar ao lugar visitado, levando-se em consideração que

[...] é portador de uma bagagem invisível, a que chamamos bagagem de cidadania ou bagagem cidadã. Se esse viajante, em sua vida infantil e adulta, foi contemplado com os direitos que lhe confere a sua condição de ser social, é muito provável que o seu comportamento frente ao meio ambiente estranho nada deixe a recriminar. Cidadão na essência do termo, tem postura digna de visitante, respeita as normas vigentes e é respeitado pelos visitados. (MOESCH, 2008, p. 90-91).

Neste artigo, estão sendo levados em consideração os costumes e hábitos dos diferentes povos e algumas tendências que guiam o desempenho do profissional do turismo na era globalizada, de forma a obter uma atuação ética. Portanto, o conhecimento mínimo quanto aos hábitos e costumes de diferentes povos ao redor do mundo pode ser um fator diferencial na carreira de um profissional do turismo. É algo quase inconcebível trabalhar com turismo, em contato direto com pessoas de diversas culturas, sem possuir o mínimo de abertura para aceitar as diferenças. Cabe, ainda, ao próprio turista a responsabilidade em obter o mínimo de conhecimento quanto à cultura do lugar que pretende visitar, de forma a serem evitados dissabores e/ou decepções, já que cada país possui suas próprias características. O refúgio na própria identidade cultural pode ser entendido como etnocentrismo, tendo em vista que:

Etnocentrismo é uma visão de mundo onde nosso grupo é tomado como centro de tudo, e todos os outros são pensados e sentidos através dos nossos valores, nossos modelos, nossas definições do que é a existência. No plano intelectual, pode ser visto como dificuldade de pensarmos a diferença: no plano afetivo, como sentimento de estranheza, medo, hostilidade, etc. (ROCHA, 1994, p. 7).

Portanto, tanto turistas, como, principalmente, profissionais do turismo não deverão ter uma atitude etnocêntrica, procurando se adaptar adequadamente às necessidades dos visitantes sem fugir da sua própria identidade cultural, gerando assim o respeito mútuo. Uma dessas necessidades é a adaptação idiomática, ou seja, o aprendizado de algum idioma estrangeiro para que esse profissional possa se comunicar e atender com qualidade os turistas que estão visitando sua região, e vice-versa. De acordo com Bourdieu (1977): 
A língua não é somente um instrumento de comunicação ou mesmo de conhecimento, mas um instrumento de poder. Não procuramos somente ser compreendidos, mas também obedecidos, acreditados, respeitados, reconhecidos. Daí a definição completa da competência como direito à palavra, isto é, à linguagem legítima como linguagem autorizada, como linguagem de autoridade. (BOURDIEU, 1977, p. 5 e 6 ).

Baseando-se no pensamento de Bourdieu, visualiza-se a importância do conhecimento de um idioma para que se possa exercer o trabalho no setor turístico. Esse conhecimento amplia horizontes e possibilita o exercício do poder. Esse poder pode ser representado pela própria capacidade de ser compreendido e por esse motivo ser mais respeitado, além de, como citado por Bourdieu, poder ser até mesmo obedecido. Atualmente, o inglês é o principal idioma mundialmente falado, conceito que implica uma quase unanimidade. Certamente, o idioma inglês é assim reconhecido devido a fatores econômicos e políticos, como explicado por Bourdieu:

A competência lingüística (como toda competência cultural) só funciona como capital lingüístico quando em relação com um certo mercado: como prova, estão os efeitos globais da desvalorização lingüística que podem operar-se brutalmente (após uma revolução política) ou insensivelmente (por uma lenta transformação das relações de força materiais e simbólicas, como, por exemplo, a desvalorização progressiva do francês em relação ao inglês no mercado internacional). (BOURDIEU, p.10, 1977).

Uma investigação mínima em relação às outras culturas ao redor do mundo, dentro do próprio país e o conhecimento de outros idiomas poderá proporcionar parte do bom desempenho dos profissionais de turismo. Obviamente, como observado na tabela de Frank Go, as características de um profissional do turismo ideal deverão atender a outras demandas.

Diante dessas demandas, a informática tem um papel interessante. $\mathrm{O}$ bom profissional do turismo tem mais uma competência em suas mãos: a habilidade no uso do computador e da Internet. Seria inevitável que o fenômeno turístico não sofresse uma adaptação a essa realidade em um mundo de tantas idas e vindas, troca instantânea de informações, idiomas diferentes, trocas culturais, amizades feitas por uma tela de computador entre pessoas que moram em diversas partes do mundo. Giddens, mais uma vez, faz uma interessante observação quanto à nova era da computação, ressaltando que:

Foram necessários 40 anos para que o rádio atingisse nos Estados Unidos uma audiência de 50 milhões. O mesmo número de pessoas estava usando computadores apenas 15 anos após a introdução dessas máquinas. Depois que a Internet se tornou disponível, foram necessários meros quatro anos para que 50 milhôes de americanos estivessem usando regularmente. (GIDDENS, p.22, 2007).

Castells (2006, p.136) afirma que "a lucratividade e a competitividade são os verdadeiros determinantes da inovação tecnológica e do crescimento da produtividade". Portanto, o surgimento da era da informática no mundo globalizado é revolucionário no sentido de que aumentou a produtividade e competitividade entre as empresas, facilitando trâmites dispendiosos em relação ao tempo e aos valores financeiros.

Giddens (1991, p.21) lembra que o surgimento do relógio mecânico foi um fator crucial para a separação entre o tempo e o espaço, pois com esse objeto poderia se obter também o controle do espaço. Logo, a Internet e suas inúmeras possibilidades no mundo globalizado refletem o quanto o espaço pouco interfere no tempo atualmente, em que as atividades econômicas ou de simples comunicação podem ser feitas instantaneamente, não importando a distância entre os envolvidos. "Em uma compra pela Internet, é desenvolvida uma fé em fichas simbólicas ou sistemas peritos (a própria Internet), que em conjunto podem ser chamados de sistemas abstratos" (GIDDENS,1991, p.73). Essa fé, dentro do setor turístico, pode ser representada pela confiança que é investida na compra de bilhetes aéreos ou pacotes de viagem através da Internet, como discutido por Bissoli:

As novas tecnologias de desenvolvimento da atividade turística provocam efeitos no consumidor e nos diferentes agentes que intervêm no processo turístico, permitindo o emprego de novos instrumentos de venda que incrementam a produtividade e permitem um melhor serviço, com custo mais baixo. As rodovias da informação, os novos meios de comunicação audiovisuais (som e imagem) e a multimídia [4], estão revolucionando a circulação 
da informação. A viagem virtual é uma realidade, por meio de CD-ROMs e da Internet, que permitem experimentar um local antes mesmo de haver o deslocamento efetivo de uma viagem. (BISSOLI, 1999, p. 57).

Portanto, o perfil do profissional de turismo deverá ser traçado de forma a atender também a essas novas expectativas. Dia após dia, é crescente o comércio pela Internet e, para se destacarem, as empresas e seus funcionários devem manter-se atualizados. Marback e Silva delineiam o perfil do profissional de turismo atual da seguinte forma:

A satisfação desta exigência requer trabalhadores especializados que dominem e introduzam tecnologias de ponta no mercado do turismo, falem outros idiomas, tenham familiaridade com a informática e facilidade no manuseio de um computador, sendo detentores e propulsores do fator vital para a sobrevivência competitiva no cenário da globalização: o conhecimento. (MARBACK; SILVA, 2005, p. 128).

Logo, quanto mais conhecimento adquirido e investimentos na própria educação, mais bem preparado o profissional do turismo se encontrará em face do mundo globalizado atual. Infelizmente, há um lado negativo da globalização, relacionado às novas exigências do mercado, o aumento no desemprego, entre outros diversos resultados. Neste estudo, diante das diversas consequências relacionadas ao surgimento da globalização, será evidenciado o fato de muitos profissionais não terem conseguido ainda se adaptar às mudanças e estarem afastados das oportunidades de emprego que estão surgindo. Assim:

Criou-se de um lado, em escala minoritária, o trabalhador polivalente e multifuncional da era informacional, capaz de operar máquinas de controle numérico e de, por vezes, exercitar com mais intensidade sua dimensão intelectual. E, de outro lado, há uma massa de trabalhadores precarizados, sem qualificação, que hoje está presenciando as formas de part-time, emprego temporário parcial, ou então vivenciando o desemprego estrutural. (ANTUNES, 2000, p. 184).

É perceptível, então, que o profissional atual de qualquer setor deverá ser polivalente em seus conhecimentos e capacidades, equiparando-se dessa forma à nova era informatizada, tanto em aspectos técnicos quanto em aspectos intelectuais, que en- volverão o conhecimento em informática, idiomas e cultura, além de se preocupar com sua postura como profissional.

Padrões foram criados para aqueles que trabalham diretamente com o atendimento ao turista, podendo estes colaborarem no intuito de que o sonho de viagem de um turista seja, ao menos, uma viagem bem-sucedida. Esses padrões se aplicam a todas as atividades relacionadas à prestação de serviços turísticos, de forma geral, seja na hotelaria, nos serviços aeroportuários, rodoviários, ou quaisquer outros, sempre envolvendo pessoas prestando serviços para outras pessoas.

Porém, muitos desses tais padrões não são seguidos no Brasil, principalmente em empresas menores que, visando ter maiores lucros com a economia de salários e gastos com empregados, contratam profissionais sem nível superior, nem conhecimento em informática e/ou língua estrangeira, como inglês e espanhol. Embora cobrem bastante pelos serviços, não os motivam a se qualificar.

Muitos dos futuros profissionais que estão se qualificando, e procuram um estágio ou primeiro emprego, para aplicar seus conhecimentos, continuam desempregados e quando contratados por essas empresas "exploradoras" não têm espaço para contribuir como poderiam, e ainda recebem salários iguais aos sem qualificação. Essa falta de motivação se torna um grande, talvez o maior, empecilho na melhoria da postura do profissional de turismo que, embora seja teoricamente exigido, e até chegue a cumprir com tais exigências, ainda é desvalorizado pelo mercado brasileiro.

Diante do encontro entre o turista e o profissional do turismo existe uma divergência de objetivos: "o primeiro entrega-se a uma atividade de prazer, o segundo trabalha. O turista chega com muitas expectativas; os anfitriões, com muita frequência, não têm a menor ideia do que devem esperar dele" (ROBINSON, 1999, p.22).

Tendo em vista o inesperado, a capacitação profissional torna-se um instrumento importante de preparo. Essa capacitação deverá visar, entre outros fatores, a educação e a disciplina dos corpos daqueles que estarão atuando em contato direto com o turista. Partindo desse processo, durante a formação de um profissional de turismo, pode-se compreender melhor a padronização comportamental deles. Foucault 
(2001) ilustra o processo de disciplina dos corpos da seguinte maneira:

Processo para repartir os indivíduos, fixá-los e distribuí-los espacialmente, classificá-los, tirar deles o máximo de tempo, e o máximo de forças, treinar seus corpos, codificar seu comportamento contínuo, mantê-los numa visibilidade sem lacunas, formar em torno deles um aparelho completo de observação, registro e notações, constituir sobre eles um saber que se acumula e se centraliza. (FOUCAULT, 2001, p.192).

Portanto, durante o processo de domesticação de $\operatorname{corpos}^{6}$ decorrente da qualificação profissional, os futuros profissionais têm um mundo de possibilidades comportamentais que passam a ser moldadas diante de regras preestabelecidas de conduta e etiqueta diante do cargo ou função que pretendem exercer.

A postura esperada de um profissional do turismo é baseada em padrões decorrentes do seu próprio preparo em um período de educação profissional e de uma padronização mundialmente aceita em relação à atividade que se pretende exercer. Assim, para se encaixar no mundo globalizado, a postura do profissional do turismo está submissa a determinadas regras, que, embora diminuam a espontaneidade e naturalidade das ações e dos movimentos desses profissionais, são necessárias para o bom desenvolvimento e aceitação dentro do mercado de trabalho atual. Logo, as empresas que fogem desse padrão, e não exige a qualificação necessária aos seus funcionários, não sobreviverá ao mercado globalizado, e às mudanças de comportamento do consumidor.

\section{Considerações Finais}

A globalização apresenta-se como um processo irreversível para a sociedade moderna atual, e qualquer esforço das nações visando anular essa tendência possivelmente resultaria num fracasso pelas conjunturas econômica, social e política que o mundo assiste.
Apresenta-se igualmente como um fenômeno ambíguo pelos efeitos positivos assim como negativos para a sociedade. Surgindo como uma força motriz e propulsora de desenvolvimento, ao mesmo tempo em que não possibilitou elevação na qualidade de vida da maior parte da população mundial.

Tal fenômeno influenciou diretamente a atividade turística, uma vez que propiciou que a cultura dos povos, seus hábitos e costumes estivessem cada vez mais próximos, conectados por meio de novas tecnologias, e interferindo-se mutuamente. Além disso, com a globalização, houve o processo de mudança no comportamento do consumidor, que a cada dia torna-se mais exigente, e cobra do mercado produtos e serviços de qualidade, que superem suas expectativas.

Os profissionais, de todas as áreas, devem se manter atentos a essas mudanças, adaptarem-se, e acima de tudo estarem em constante processo de qualificação para atender as exigências desse consumidor.

No turismo, por exemplo, o profissional deve seguir "regras" para poder se encaixar no mercado de trabalho. A espontaneidade de seu comportamento será contida durante a realização de alguma função no setor turístico, tendo em vista que os padrões existem e em torno deles estão definidas regras comportamentais.

O conhecimento mínimo quanto à cultura dos turistas, o conhecimento mínimo em algum idioma, especialmente o inglês, entre outras exigências, possibilitarão grandes oportunidades de sucesso profissional. Assim, ele deverá ser polivalente e procurar manter-se atualizado.

Portanto vale citar Witte (2006), que em seu livro Business English: a pratical approach define que "o profissional de hoje precisa manter-se informado: em um mundo cada vez mais globalizado, um profissional de qualquer área [...] terá a necessidade de ler sobre todas elas (áreas), e não somente sobre sua atividade de atuação, porque é preciso ter uma visão global do mundo". A globalização não nos permite o atraso ou desleixo quanto á atualização tecnológica. $\mathrm{O}$ mundo está em constante movimento.

\footnotetext{
${ }^{6}$ A expressão "domesticação de corpos" é inspirada no texto Corpos Dóceis, o primeiro capítulo do livro Vigiar e Punir (FOUCAULT, 1987), onde o autor cita os processos disciplinares "que permitem o controle minucioso das operações do corpo, que realizam a sujeição constante de suas forças e lhes impõem uma relação de docilidade-utilidade" ( FOUCAULT, 1987, p.118).
} 


\section{Referências}

ANSARAH, M. Formação e capacitação profissional em turismo e hotelaria. São Paulo, Aleph, 2002.

ANTUNES, R. Adeus ao trabalho? ensaio sobre as Metamorfoses e a centralidade do mundo do trabalho. 7. ed. rev. ampl. Campinas: Cortez, Ed. da Unicamp, 2000.

BEDIN, G. A. Estado, cidadania e globalização do mundo: algumas reflexões e possíveis desdobramentos. In: OLIVEIRA, O. M. O. (Coord.). Relações internacionais e globalização: grandes desafios. Ijuí: Ed. Unijuí, 1997.

BAUMAN, Z. Globalização: as consequências humanas. Trad. Marcus Penchel. Rio de Janeiro: Jorge Zahar, 1999.

BISSOLI, M. A. M. A. Planejamento turístico municipal com suporte em sistemas de informação. São Paulo: Futura, 1999.

BOURDIEU, P. A economia das trocas lingüísticas. In: . ORTIZ, R. (Org.). Pierre Bourdieu: sociologia. São

Paulo. Ed. Ática. 1983. p.156-183. Disponível em:<http:// antropologias.descentro.org/files/downloads/2011/05/ Pierre-Bourdieu-A-economia-das-trocas-simbólicas.pdf $>$. Acesso em: 28 fevereiro 2011.

CASTELLS, M. A sociedade em rede: a era da informação: economia, sociedade e cultura. 9. ed. São Paulo: Paz e Terra, 2006. v.1.

COOPER, C.; SHEPHERD, R.; WESTLAKE, J. Tourism and hospitality education. Guildford: University of Surrey, 1994.

Educando os educadores em turismo: manual de educação em turismo e hospitalidade. São Paulo: Roca, 2001.

FOUCAULT, M. Vigiar e punir: a história da violência nas prisões. 24.ed. Petrópolis: Vozes; 2001.

GIDDENS, A. As consequências da modernidade. São Paulo: Editora UNESP, 1991.

Record, 2007.

- Mundo em descontrole. 6. ed. Rio de Janeiro:

GO, F. M. A globalização e os problemas educacionais do turismo emergente. In: THEOBALD, William F. (Org.). Turismo global. São Paulo: Editora SENAC, 2001.

JAFAR, J.; RICHIE, J. B. Towards a framework for tourism education: problems and prospects. Annals of Tourism Research, v. 8, n. 1, 13-33, 1981.

KOTLER, P. Marketing 3.0: as forças que estão definindo o novo marketing centrado no ser humano. Rio de Janeiro: Elsevier, 2010.

MARBACK, G. Neto; SILVA, J. A. S. Turismo: visão e ação, v. 7, n. 1, jan./abr. 2005.
MOESCH, N. M. Turismo: virtudes e pecados. In: GASTAL, S. (Org). Turismo: 9 Propostas para um saber fazer. 4. ed. Porto Alegre: ediPUCRS, 2008, p. 85-93. Disponível em: $<$ http// www.periodicodoturismo.com. $\mathrm{br} /$ site/artigo/pdf/a $\% 20$ Pratica $\% 20$ do $\% 20$ turismo $\% 20$ pedag\%c3\%93gico.pdf>. Acesso em: 02 março 2011.

MOTA, K. C. N. Egressos do curso de hotelaria do Instituto Federal do Ceará: Perfil de satisfação e relação com o mercado. In: MOTA, K.C.N; ARAGÃO, A. R. F. (Orgs.). Educação Tecnológica: teoria e prática do turismo, da hospitalidade e do lazer - Fortaleza, CE: Expressão Gráfica Editora, 2011.

RAKADJIYSKA, S. G. Tourism training and education in Bulgaria. Annals of Tourism Research, v. 17, p. 150153,1990 .

ROBINSON, M. Por um turismo consensual. O Correio da UNESCO, Brasília: set./out., p. 22-23, 1999.

ROCHA, E. O que é o etnocentrismo. São Paulo: Brasiliense, 1994.

SALGADO, M.; M. M.; COSTA, C.; CURADO, H. A formação no setor do turismo: o caso de Portugal. In: SHIGUNOV NETO, A.; SHIZUE, B. MACIEL, L. (Orgs.). Currículo e formação profissional nos cursos de turismo. Campinas, SP: Papirus, 2002.

SANTOS, M. Técnica espaço e tempo: globalização e meios técnico científico. 3.ed. São Paulo: Hucitec, 1997

SANTOS, B. S. Os processos de globalização. In: SANTOS, B. S. (Org.). A globalização e as ciências sociais. 2. ed. São Paulo: Cortez, 2002.

SILVA, E. V. M. A influência do paradigma do turismo na construção dos corpos dos profissionais da área. 2007. Disponível em: <http//www.periodicos.udesc.br/index.php/ linhas/article/view/1196/1011>. Acesso em: 27 fevereiro 2011.

SPINELLI, S. A importância da formação profissional em turismo. In: SHIGUNOV NETO, A.; MACIEL, L. (Orgs.). Currículo e formação profissional nos cursos de turismo. Campinas, SP: Papirus, 2002, p. 105-126.

QUEVEDO, M. Turismo na era do conhecimento. Florianópolis: Pandion, 2007.

WITTE, R. E. Business english: a practical approach. 2. ed. São Paulo: Saraiva, 2006.

Recebido em: 29 de janeiro de 2013 Aceito em: 29 de abril de 2013 